\title{
Impacts of changing climate on the distribution of migratory birds in China:habitat change and population centroid shift
}

\author{
Jie Liang ${ }^{1}$, Yuhui Peng ${ }^{1}$, Wenle Xing ${ }^{1}$, Xiaodong Li $^{1}$, Ming Yan ${ }^{1}$, Yujie Yuan ${ }^{2}$, Xin Li $^{1}$, \\ and Ziqian $\mathrm{Zhu}^{1}$ \\ ${ }^{1}$ Hunan University \\ ${ }^{2}$ Affiliation not available
}

May 5, 2020

\begin{abstract}
Climate changes has been shown to be related to the changes in the distributions of migratory species, which irreparably harms biodiversity. In this study, we evaluated the habitat change and population centroid shift for 7 orders and 23 different species on the IUCN (International Union for the Conservation of Nature and Natural Resources) Red List of migratory birds from 2014-2017 in current to mid-21st (2041-2700) century by Maximum Entropy method (MaxEnt) model. We found striking spatial variation in the suitability in geography, with Yangtze River basin losing 9.74\% of suitable habitat and Pearl River basin losing $13 \%$ of habitat. The area of suitable habitat decreases over $3 \%$ of total habitat area in China under the RCP2.6, and decreases about $10 \%$ of total habitat area in China under RCP 8.5 scenario, with the population centroid of habitat moving about $50 \mathrm{~km}$ to northeast on average. Furthermore, the suitability of migratory birds will decrease over $3 \%$ in future, which will be difficult for migratory birds to survive. The direction and distance of population centroid are different for every species. Most of the individual species in the study will move over $50 \mathrm{~km}$ and all the species will move towards to places with higher suitability. For the whole of China, the constraint for migratory birds is t_min. The dominant variable in southeast China is NDVI, and the northern China is altitude (alt). The decline in suitable habitat area and shift in population centroid will lead to the changes in the time and distance of migration process, resulting in more adverse conditions for the survival of migratory birds. Our study proves the adverse role of climate change in species distribution which is a prerequisite for protecting species in future.
\end{abstract}

\section{Impacts of changing climate on the distribution of migratory birds in China:habitat change and population centroid shift}

Jie Liang ${ }^{\mathrm{a}, \mathrm{b}^{*}}$, Yuhui Peng ${ }^{\mathrm{a}, \mathrm{b}}$, Wenle Xing ${ }^{\mathrm{a}, \mathrm{b}}$, Xiaodong $\mathrm{Li}^{\mathrm{a}}{ }^{\mathrm{a} b}$, Ming Yan ${ }^{\mathrm{a}, \mathrm{b}}$, Yujie Yuan ${ }^{\mathrm{c}}$, Xin Li ${ }^{\mathrm{a}, \mathrm{b}}$, Ziqian Zhu ${ }^{\mathrm{a}, \mathrm{b}}$

${ }^{a}$ College of Environmental Science and Engineering, Hunan University, Changsha 410082, P.R. China

b Key Laboratory of Environmental Biology and Pollution Control (Hunan University), Ministry of Education, Changsha 410082, P.R. China

${ }^{c}$ Key Laboratory of Ecological Impacts of Hydraulic-Projects and Restoration of Aquatic Ecosystem of Ministry of Water Resources, Institute of Hydroecology, Ministry of Water Resources and Chinese Academy of Sciences, Wuhan, 430079, P.R. China

\section{Abstract:}

Climate changes has been shown to be related to the changes in the distributions of migratory species, which irreparably harms biodiversity. In this study, we evaluated the habitat change and population centroid shift for 7 orders and 23 different species on the IUCN (International Union for the Conservation of Nature and 
Natural Resources) Red List of migratory birds from 2014-2017 in current to mid-21st (2041-2700) century by Maximum Entropy method (MaxEnt) model. We found striking spatial variation in the suitability in geography, with Yangtze River basin losing 9.74\% of suitable habitat and Pearl River basin losing 13\% of habitat. The area of suitable habitat decreases over $3 \%$ of total habitat area in China under the RCP2.6, and decreases about $10 \%$ of total habitat area in China under RCP8.5 scenario, with the population centroid of habitat moving about $50 \mathrm{~km}$ to northeast on average. Furthermore, the suitability of migratory birds will decrease over $3 \%$ in future, which will be difficult for migratory birds to survive. The direction and distance of population centroid are different for every species. Most of the individual species in the study will move over $50 \mathrm{~km}$ and all the species will move towards to places with higher suitability. For the whole of China, the constraint for migratory birds is $t_{\min }$. The dominant variable in southeast China is NDVI, and the northern China is altitude (alt). The decline in suitable habitat area and shift in population centroid will lead to the changes in the time and distance of migration process, resulting in more adverse conditions for the survival of migratory birds. Our study proves the adverse role of climate change in species distribution which is a prerequisite for protecting species in future.

\section{Introduction}

The number of migratory birds has declined dramatically worldwide since 1970 (Ims et al., 2019; Spooner et al., 2018). Key driver of the abundance decline is that climate change exacerbates the survival pressure of migratory birds (Jacome et al., 2019; Jetz et al., 2007; Lehikoinen et al., 2019; Mammola et al., 2018; Pearson et al., 2013; Russell et al., 2015; Saino et al., 2011; Spooner et al., 2018; Wilson et al., 2019; Yalcin \& Leroux, 2018; Yu et al., 2019), which will result in the ecological imbalance and the absence of ecological function (Cohen et al., 2018; Hewson et al., 2016; Keogan et al., 2018). It is critical to understand how species spatial distribution changes under the changing climate for protecting biodiversity and formulating the effective policies (Northrup et al., 2019; Vickery et al., 2014).

In past decades, bird populations have declined and habitat has changed a lot. Roberts et al.(2019) assessed the change of avian spatial regimes and population in 46 years but did not explain the reason (Roberts et al., 2019). Previous studies have made great progress in studying the correlation between habitat distribution and climate change. Brawn et al.(2017)illustrated that the population of tropical birds was closely correlated to the climate in rainfall (Brawn et al., 2017). Climate change damages the region's suitable environmental conditions for certain species (Sanchez-Bayo \& Wyckhuys, 2019; Title \& Bemmels, 2018), which leads to change in their geographic range (Keogan et al., 2018; Saino et al., 2011). Climate change makes that the growth cycle of migratory birds hardly keep the match between the feeding time and the period of rich food resources (Bowler et al., 2019; Fecchio et al., 2019; Jetz et al., 2007; Kentie et al., 2018; Wilson et al., 2019). Bowler et al.(2019) corroborated the general trend that European insectivorous birds communities was confirmed to be the same as insect (Bowler et al., 2019). Saino et al.(2011) confirmed the reason of the population decline of European migratory birds was that their migration phenology mismatches the climate (Saino et al., 2011). Despite these lines of evidence, little research has been done to identify the effects of individual climate variables on species distribution. Better identification of major climate variables can help to establish effective policies, which is one of the urgent needs for biodiversity conservation (Beringer et al., 2011; Both et al., 2010; Cohen et al., 2018; Dugger et al., 2016; Hoffmann \& Sgro, 2011).

Theoretical research on the correlation between species distribution and climate change is meaningful to protect biodiversity. To understand the effect of climate change on the potential distribution pattern of species, research model has become an important means. Saupe et al.(2019) demonstrated the MaxEnt model performed well for evaluating the changes in the distribution of birds at the geographical level (Saupe et al., 2019). The presence data is widely used in the species distribution model combing with climate data and proved to be feasible (Finch et al., 2017; Jacome et al., 2019; Roberts et al., 2019; Saupe et al., 2019).

In this study, we combined bird sample data and China national scale climate data to build the species distribution models(SDMs) for 7orders of migratory birds and 23species in different level on the IUCN red list (Moran \& Kanemoto, 2017). In the study, we explored the current distribution and the drivers by 
MaxEnt, and discussed where and how the distribution may change in the 2050s. Firstly, we used the model to simulate the current distribution of migratory birds and predicted their distribution under the future scenarios. Secondly, based on the simulation of birds' distribution, we quantified the movement trend by calculating the species population centroid and identified the individual contribution of environmental variables. Lastly, we compared the differences between the distribution and the protected areas to discuss the effective methods for reducing the biodiversity loss.

1.

\section{Material and methods}

\section{Species data}

Migratory birds transport the energy and nutrients within and between the ecosystems, which is the largest population movement in the world, connecting the world into a huge ecosystem (Bauer \& Hoye, 2014; Russell et al., 2015). The population of migratory birds passing through the major flyways dropped by half over the past 30 years (Runge et al., 2015) and migratory birds got into an unfavorable position in Asia (Kirby et al., 2008).

China is the largest country in Asia lying in East Asian-Australasian flyways with high biodiversity (Ma et al., 2019).We compiled migratory bird data from 2014-2017 Bird Report(http://www.birdreport.cn/). The Bird Report is the most complete and effective summary by bird watchers in China, accounting for $80 \%$ of all bird species, and each birdwatching record is sorted up and reviewed by experts to ensure accuracy. The latitude and longitude of the location were determined by comparing the geographical locations in Google Earth. We recorded the bird presence data in ArcGIS10.2, and selected 7 orders of migratory birds, including 115 species, covering 12156 geographical records. 23 species are endangered species on the IUCN red list(Fig1) (Garnett et al., 2003; Young et al., 2014). After deleting the duplicate invalid data, we modelled the potential distribution of both 7 orders of migratory birds and 23 different IUCN categories species, including 3 critically endangered (CR) species, 5 endangered (EN) species, 9 vulnerable(VU) species and 6 near threatened(NR) species(Table S1). The locations of migratory birds is showed in Fig.1.

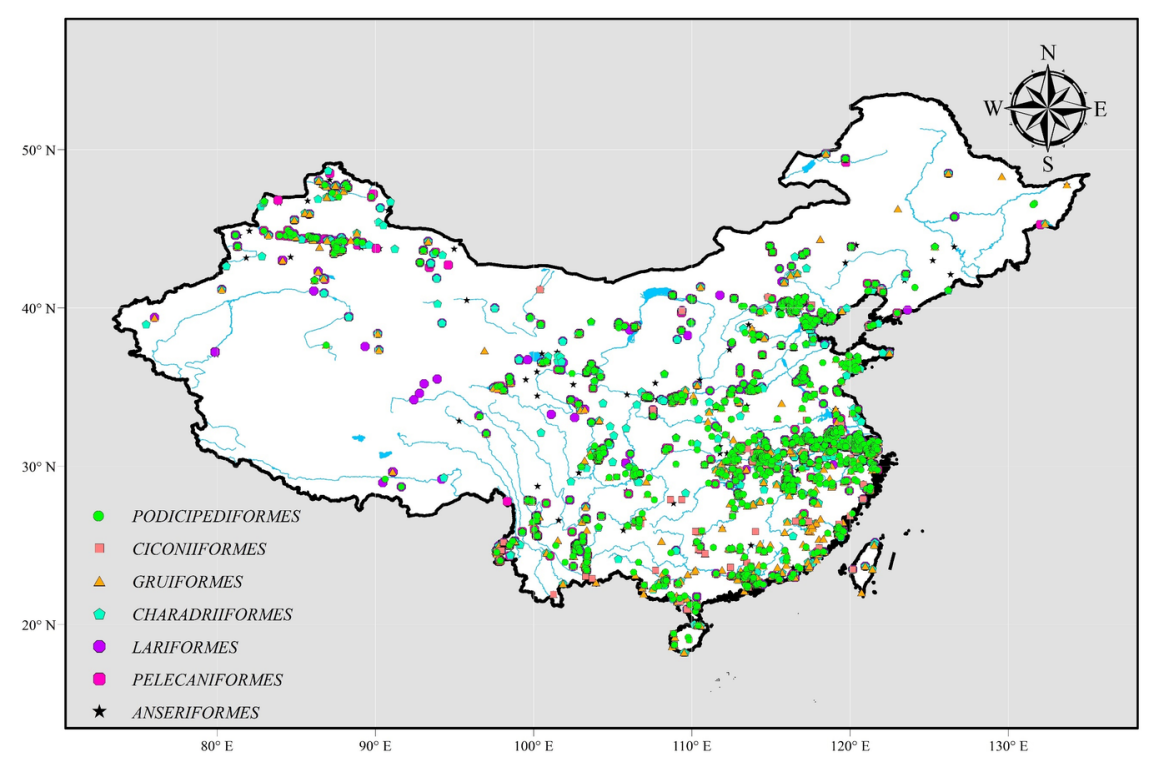




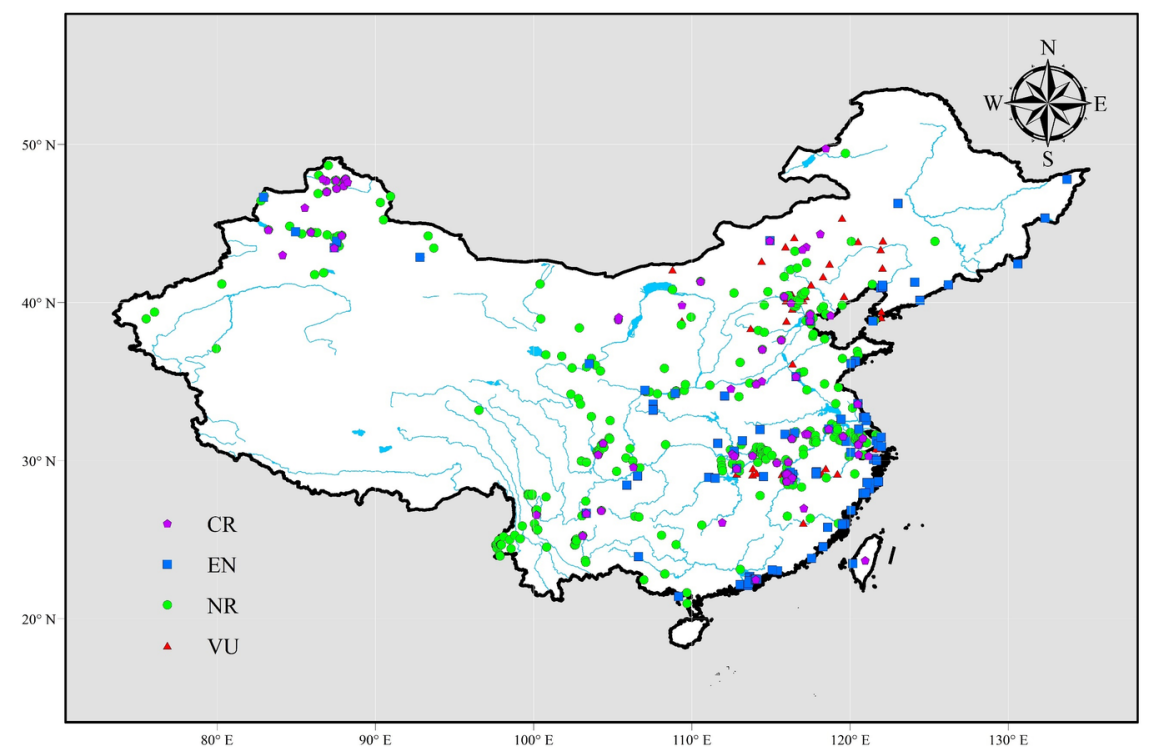

Fig. 1. The locations of (a) 7orders of migratory birds and (b) 23 different IUCN categories species.

\section{Climate data and the scenarios}

We only used static environmental variables to simulate the potential distribution of migratory birds, and focused on and analyzed the factors the static environmental factors that are known to affect birds' movement and habitat changes (Arribas et al., 2019; Beumer et al., 2019). The data of bioclimate, temperature and precipitation were imported to the model from Worldclim 1.4 dataset(http://www.worldclim.org/ ) with 30 arcseconds(about $1 \mathrm{~km}$ ) resolution ratio. Current climate scenario(average 1970-2000) is used to comprehend the latent distribution while two future scenarios(RCP2.6 and RCP8.5 during average 2040-2060) are used to estimate the future distribution shift. The RCP2.6 is an optimistic scenario and the RCP8.5 is an pessimistic scenario (Boisvert-Marsh et al., 2019; Rosen \& Guenther, 2016). The land cover dataset and the NDVI dataset were downloaded from the resource and environment data cloud platform (http://www.resdc.cn/) with a resolution of $1 \mathrm{~km}$. The reserves data were from the protected planet(https://www.protectedplanet.net/). The distance of each grid to protected area was calculated by Euclidian distance in ArcMap. Altitude and slope were compiled by using the Digital Elevation Model(DEM) from the Geospatial Data Cloud (http://www.gscloud.cn).

To make the result reasonable, the Pearson Correlation Coefficient (PCCs) was used to remove high correlated variables(Table S3) Moreover, 13 variables were retained in the model(Table1) after removing high correlated bioclimate variables $(|\mathrm{r}|>0.8)$.

Table1 List of variables used in MaxEnt modelling.

\begin{tabular}{ll}
\hline Abbreviation & Variables \\
\hline bio1 & Annual Mean Temperature \\
bio2 & Mean Diurnal Range \\
bio3 & Isothermality \\
bio7 & Temperature Annual Range \\
bio13 & Precipitation of Wettest Month \\
bio14 & Precipitation of Driest Month \\
bio15 & Precipitation Seasonality (Coefficient of Variation)
\end{tabular}




\begin{tabular}{ll}
\hline Abbreviation & Variables \\
\hline bio18 & Precipitation of Warmest Quarter \\
NDVI & Normalized Difference Vegetation Index \\
$t_{\min }$ & Minimum temperature \\
$t_{\max }$ & Maximum temperature \\
LUCC & Land cover \\
alt & Altitude \\
dis_p & Distance to the protected area \\
slo & Slope \\
prec & Precipitation \\
\hline
\end{tabular}

\section{Species distribution model and inspection}

All SDMs use the correlation between the species sample data and environmental variables to estimate the ecological niche of the species according to a specific method and show the correlation to the studied area (Panda \& Behera, 2019; Thorson, 2019; Wang et al., 2019; Yu et al., 2019). We predicted the distribution of birds by using the MaxEnt model, which only uses existing events to study the principle of balance and simulates the absent data from the background(Manish \& Pandit, 2019). It defines the correlation between species and the environment variables, and predict the distribution according the present sample data (Dudik et al., 2007; Dudik et al., 2004; Phillips et al., 2006; Phillips \& Dudik, 2008). The distribution which has the highest entropy is selected to be the optimal distribution from all the eligible distribution.

We used the default settings and divided the data into two parts, $75 \%$ for modeling and $25 \%$ for evaluating. The jackknife test was done in MaxEnt to recognize the importance of variables, and the benefit of the test is to give the approximate confidence intervals for many parameters (Jacome et al., 2019; Shcheglovitova \& Anderson, 2013).

The Area Under Curve (AUC), the proportion under the Receiver Operating Characteristic Curve (ROC), was used to evaluate the performance of model (Phillips et al., 2006). The AUC value is positively correlated with the model, so we picked the model with AUC value over 0.8 seeing at Table S2 (Elith et al., 2011; Fourcade et al., 2014).

\section{Index of habitat change}

\subsubsection{The habitat loss}

The decrease of habitat area is the main threat to the decline in biodiversity which is caused by climate change (Taubert et al., 2018). There is a continuous distribution suitability map coming from the model. To calculate the habitat loss, the "maximum training sensitivity plus specificity logistic threshold(MaxSSS)" was used to classify the continuous distribution suitability into the binary distribution map (Saupe et al., 2019; Vale et al., 2014). We also calculated the mean suitability of the map. The calculating of habitat loss is based on the comparison between the suitable area in current and future scenarios. It was described as habitat loss when the suitable area turns to the unsuitable area and the opposite is habitat gain..

\subsubsection{The population centroid}

The population centroid is regarded as the represented indicator reflecting the population movement process (Collins et al., 2017; Liu et al., 2019).We calculated the population centroid of the habitat for migratory birds in longitude (X) and latitude (Y) to explain the bias in future. After compared the population centroid of the species, we take the average offset distance in two scenarios

$\mathrm{X}=\frac{\sum X_{i} P_{i}}{P} \mathrm{Y}=\frac{\sum Y_{i} P_{i}}{P}$

where $X_{i}$ and $Y_{i}$ is the longitude and latitude of the site, and $P_{i}$ is the sustainability at site, and $\mathrm{P}$ is the total sustainability . 
1.

\section{Results}

\section{Spatial changes of habitat and the shift of population centroid}

Based on the current and the two future scenarios, the models simulated the distribution of 7 orders of migratory birds and the endangered birds well by checking the AUC value(Table S1). The current and future potential geographical distribution of birds in China is shown in Fig.S1.

Table 2. Result of models assessing how climate influence the habitat change.

\begin{tabular}{lllllll}
\hline & Current & Current & RCP2.6 & RCP2.6 & RCP8.5 & RCP8.5 \\
\hline & $\begin{array}{l}\text { Percentage } \\
(\%)\end{array}$ & Area $\left(10^{4} \mathrm{~km}^{2}\right)$ & percentage $(\%)$ & $\begin{array}{l}\text { Area }(10) \\
\left(10^{4} \mathrm{~km}^{2}\right)\end{array}$ & percentage $(\%)$ & Area $\left(10^{4} \mathrm{~km}^{2}\right)$ \\
Suitable & 16.43 & 157.73 & 16.07 & 154.27 & 14.69 & 141.02 \\
Unsuitable & 83.56 & 802.18 & 83.93 & 805.73 & 85.31 & 818.98 \\
Habitat loss & & & 11.04 & 17.41 & 19.00 & 29.97 \\
Habitat gain & & 8.82 & 12.93 & 8.41 & 13.27 \\
\hline
\end{tabular}

The suitable area of migratory birds in the current climate accounts for $16.43 \%$ of total area of China. In the future scenario, the percentage of the suitable area are $16.07 \%$ of total area of China in RCP2.6 and $14.69 \%$ of total area of China in RCP8.5. Compared with the current climate, the suitable area decreases by $0.36 \%$ of total area of China under RCP2.6 scenario and $1.74 \%$ of total area of China under RCP 8.5 scenario. The habitat transformation in future is shown in Fig 2. Display in accordance with the calculation results, the habitat area will decrease (Rushing et al., 2016; Saino et al., 2011). The habitat change for 7 orders of migratory birds is shown in Fig.S2.

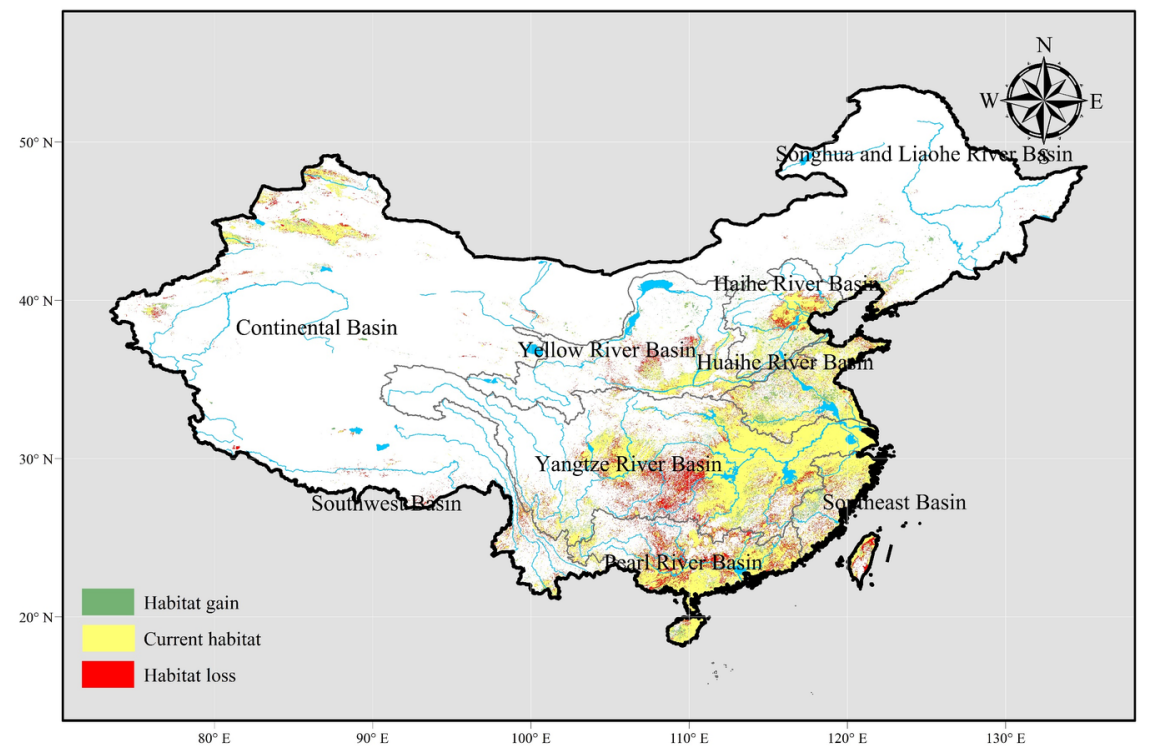




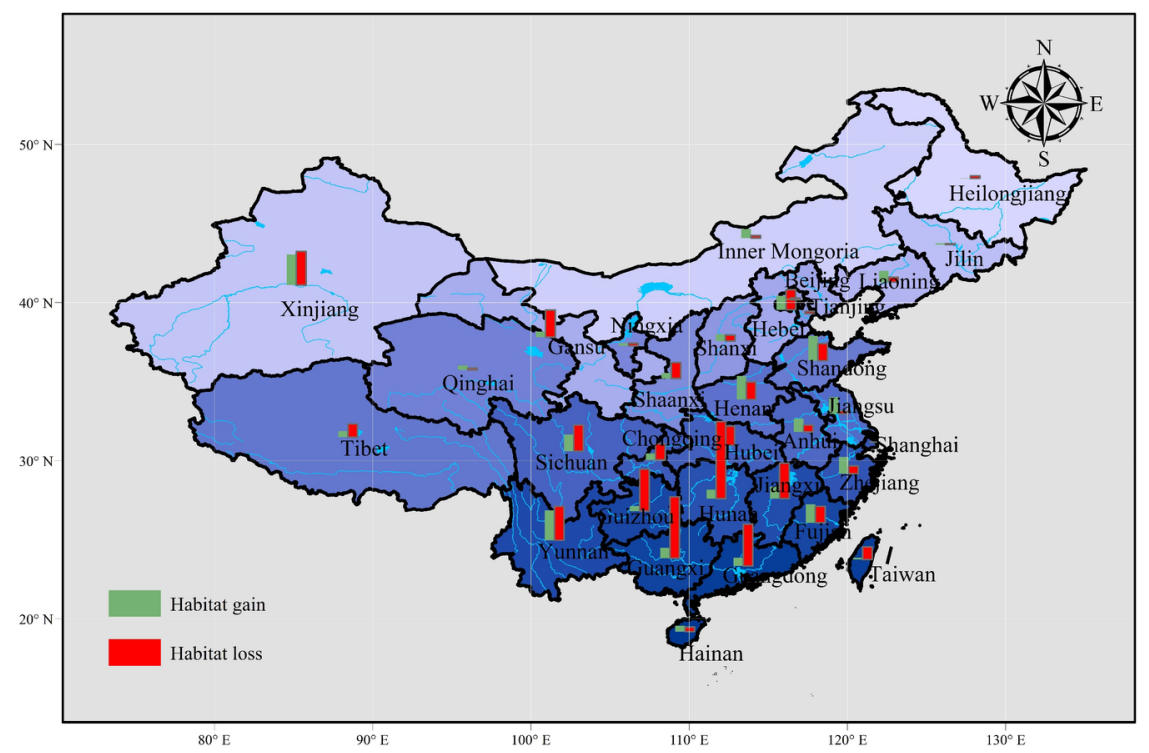

Fig. 2. (a)The habitat change in future and (b) the statistics of habitat change in province

Prediction models for future scenarios show the decrease of suitable regions (Bay et al., 2018). The area most prone to qualitative change in future is the boundary zone with low altitude between suitable and unsuitable areas. The most loss of habitat is mainly located in the southern China, including the Hunan province, the Guangxi Zhuang Autonomous Region and Guangdong province. Hunan will be the province with highest habitat loss in future with losing $26,361 \mathrm{~km}^{2}$ accounting for $20.74 \%$ of the current total habitat area in Hunan. Guangxi Zhuang Autonomous Region will loss $19767 \mathrm{~km}^{2}$ accounting for $18.50 \%$ of the current total habitat area in Guangxi. Guangdong province will loss $12985 \mathrm{~km}^{2}$ accounting for $11.78 \%$ of the current total habitat area in Guangdong. The abatement of habitat is common in China except some places (Fig.2). The most gain of habitat is located in the southeast China, including Jiangsu province, Zhejiang province and Shandong province. The habitat area will rise $5396 \mathrm{~km}^{2}$ in Jiangsu province, $3460 \mathrm{~km}^{2}$ in Zhejiang province and $2970 \mathrm{~km}^{2}$ in Shandong province.

In this study, the research content of 7 orders of migratory birds revealed an obvious bias trend in the population centroid of habitat. In future climate scenarios, the entire population centroid will moved to the northeast, and all the migratory birds will move from their potential habitats to higher altitudes (Pacifici et al., 2017). The mean suitability is shown the decline in future (Fig.S3).

Table 3. The shift situation of migratory birds.

\begin{tabular}{lll}
\hline Orders & Shift direction & Shift distance $(\mathrm{km})$ \\
\hline All migratory birds & Northeast & 51.01 \\
PODICIPEDIFORMES & Northeast & 49.00 \\
CICONIIFORMES & Northeast & 24.88 \\
GRUIFORMES & Northeast & 66.17 \\
CHARADRIIFORMES & Northeast & 52.74 \\
LARIFORMES & Northeast & 73.63 \\
PELECANIFORMES & Northeast & 43.55 \\
ANSERIFORMES & Northeast & 45.04 \\
\hline
\end{tabular}


Habitat loss and shift of the population centroid will make migration process more difficult. The habitat loss also deteriorates the connectivity between adaptation areas (Finch et al., 2017). The migratory birds have less food on the flyways and have to fly longer distance to achieve the migration. These conditions do not only make the migration process harder, but also retains many birds from completing the process. Migratory species require appropriate survival conditions throughout their whole migration process, including the breeding process, the wintering process and the migration between the 2 process (Rushing et al., 2016). Climate change may affect the 3 process all and lead species to spend more energy and time to migrate. With the increasing of distance and the unstable of food, the difficulty of survival for migratory species will increase (Finch et al., 2017; Rushing et al., 2016; Saino et al., 2011). Especially for the long-distance migration, the risk of death will increase a lot (Bauer \& Hoye, 2014; Kirby et al., 2008; Yong et al., 2018).

\section{The importance of environment variables}

The percentage contribution of different variables can be seen by the jackknife test in the MaxEnt model. The determination of the leading factor for the migratory birds is derived from the comparison of the contribution rate of the environmental variables involved in the model.

The result of estimating the importance of variables showed that $t_{\min }$ was the most crucial environmental variable for distribution of migratory birds, accounting for $23.02 \%$ importance. The LUCC, alt, bio1 and NDVI also made massive contributions to the model, accounting for $15.2 \%, 18.64 \%, 12.97 \%$ and $12.22 \%$ importance respectively. The sum of the 5 essential variables accounted for $82.05 \%$ of the cumulative contribution rate. The individual contribution of these variables can be seen in Fig 3a.

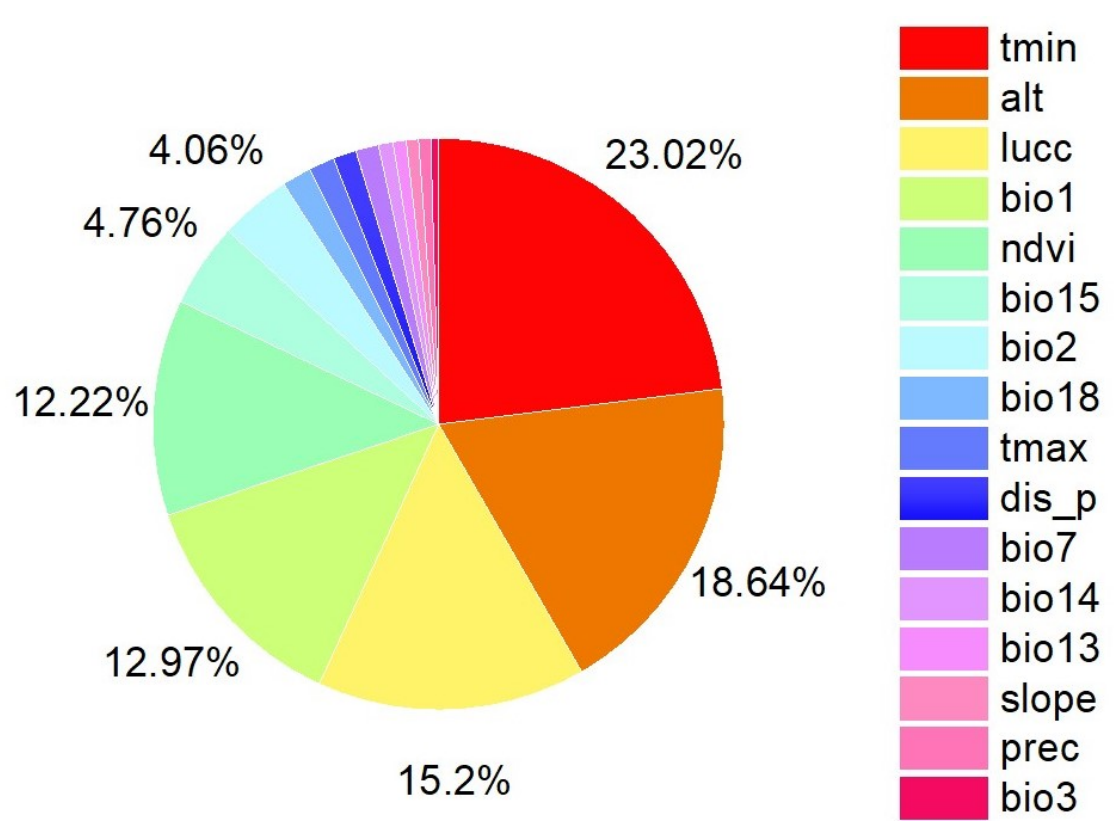




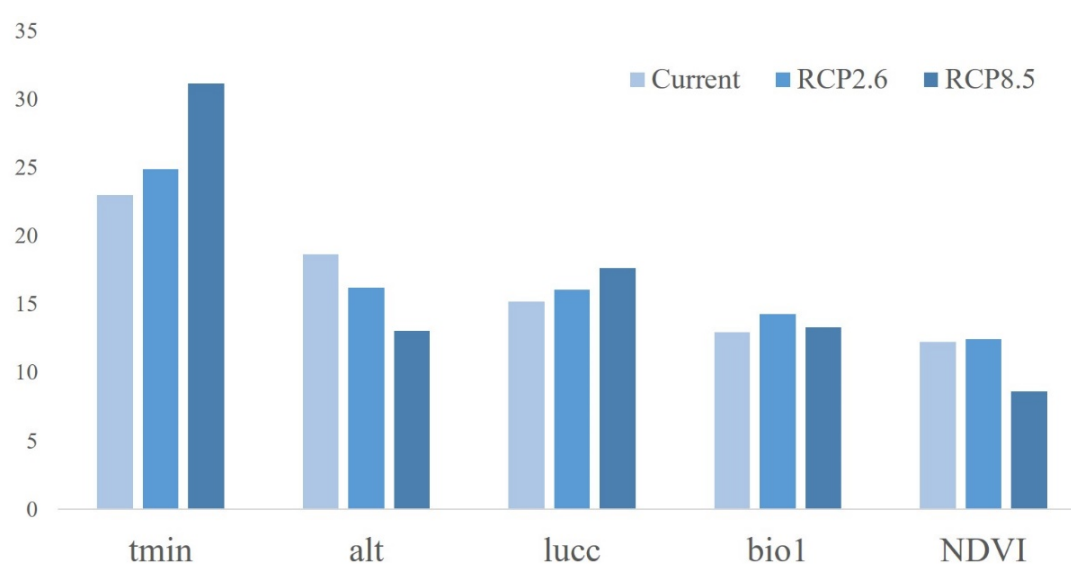

Fig. 3.(a)The percent contribution of the environment variables in current distribution of birds(b) The comparison of percentage contribution of 5 essential variables in different scenarios

This result indicated the 5 factors were of great significance for the current distribution of birds. In the future scenarios, the most important variable is still $t_{\min }$, of which the percent contribution is $23.89 \%$ in RCP2.6 and $31.17 \%$ in RCP8.5(Fig.3b). It can be seen that the temperature is the main environmental factor that affects the potential distribution area of the migratory birds. The combined percent contribution of all climate variables are $53.59 \%$ in RCP2.6 and 59.13\% in RCP8.5, and climate change still has a great influence on the distribution of migratory birds in future.

The appropriate living conditions of the migratory birds can be viewed through the single-factor response curves of 5 most important environmental variables (Fig.S2). From the 5 most important variables, we can know that birds prefer to live in the plains with a warm climate and abundant water resources (Ma et al., 2019; Yong et al., 2018). Flat terrain means flying distance to search food is shorter and consuming energy is less. The warm climate and rich water resources mean food resources are rich for the migratory birds (Myers et al., 2000). When the temperature changes, the suitable area of the migratory birds shifts. The transferred area may overlap with the human living space, which will cause the living space for migratory birds to be compressed(Fournier et al., 2019).

\section{The distribution of endangered species}

The distribution of endangered species is always used in the division of protected areas (Lehikoinen et al., 2019; Manish \& Pandit, 2019; Runge et al., 2015; Sang et al., 2011; Shen et al., 2015; Xu et al., 2017), which identifies areas that need priority protection and has positive implications for planning and constructing of protected areas. 23 species of different endangered level on the IUCN red list were used in our model to comprehend the current potential distribution and the future habitat. The comparison between the current situation and future distributions of species is showed in Fig.4. 

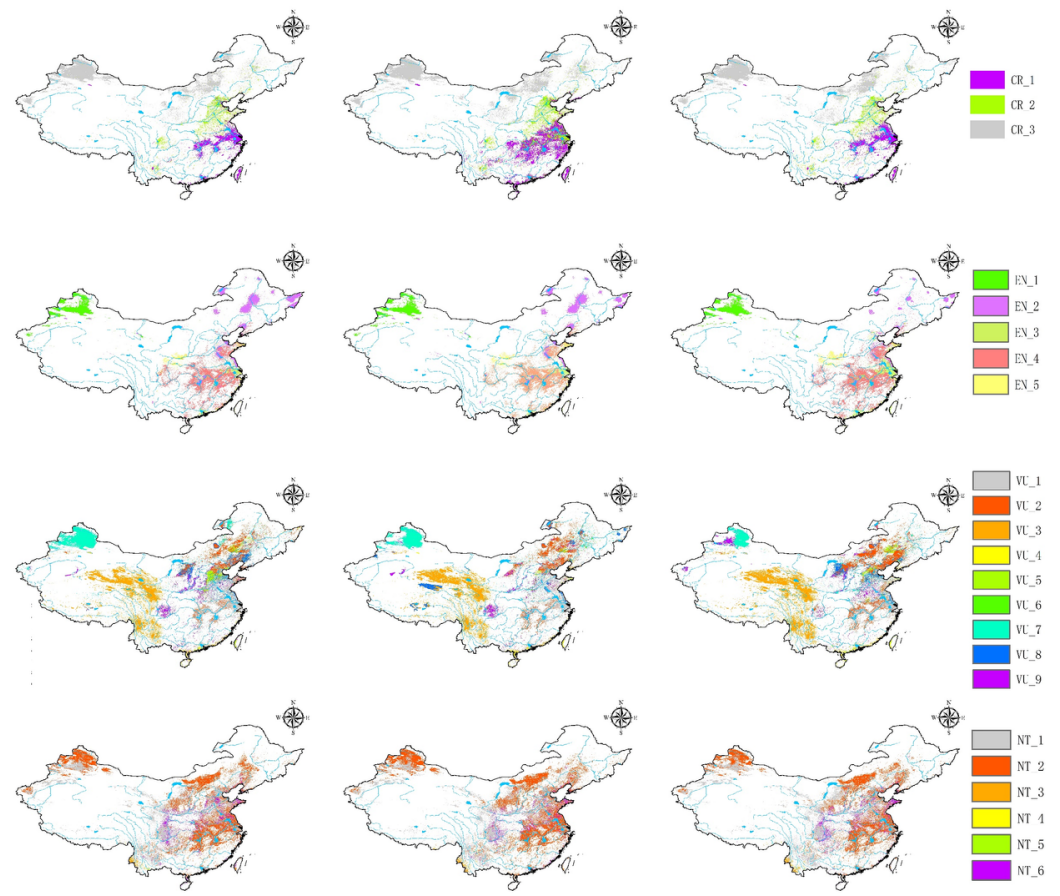

Fig. 4. Habitat of the species groups identified by MaxEnt. Each panel depicts the habitat of each bird group based on the different scenarios.

The distributions of most endangered species have changed by comparing the distributions of present and future climate scenarios. The distributions of 9 species are shown a distinct reduction in distribution and 8 species will maintain their current habitat area. The habitats of CR_3, CR_1, VU_3 and EN_4 decease $56001 \mathrm{~km}^{2}, 26652 \mathrm{~km}^{2}, 44464 \mathrm{~km}^{2}$ and $56608 \mathrm{~km}^{2}$. The species that maintain the existing habitat area mainly include EN_3, CR_2 and EN_1.Specifically, the habitats of several species will expand under the influence of climate change in future. All the expand species are mainly distributed in Shangdong and Hebei province of the middle-eastern China, consistent with total distribution (Northrup et al., 2019; Shen et al., 2015).

Not only the distributions have changed greatly, but also the population centroids shift a lot(Fig.5a, the abbreviation of species in shown at Table.S4). The estimation of birds' population migration direction on a large scale is not effective for small areas. The population centroid of migratory birds, shifting in small scale areas, are easily influenced by the local topography, and could not match with the total shift of birds in country scale. The migration direction of each species is different and the offset distance is different.

Species distribution will change obviously in future by detecting from the population centroid. The population centroids of most species migrate long distances from the current centroids. In particular, some population centroids of critically endangered species have experienced a huge offset in future. Especially CR_3 will move $292.88 \mathrm{~km}$ to southeast with the mean suitability decreasing $2.67 \%$, which may exacerbate the survival crisis. The endangered species will also change greatly in future as EN_2 moving $197.36 \mathrm{~km}$ to southwest and EN_5 moving $174.16 \mathrm{~km}$ to northwest. The most distributions of vulnerable species will move long distances from the current and easily get adverse effects from climate change. In future, VU_8 will move $327.74 \mathrm{~km}$ towards southwest with mean suitability decreasing $30.56 \%$ and VU_7 will move 419 $\mathrm{km}$ to southeast with mean suitability decreasing $10.82 \%$. In general, species distribution at high latitudes may move southward in future with the decline in mean suitability. Species distribution at middle latitudes may move eastward. The movement of species means that their habitats are compressed and the living risk rise. 

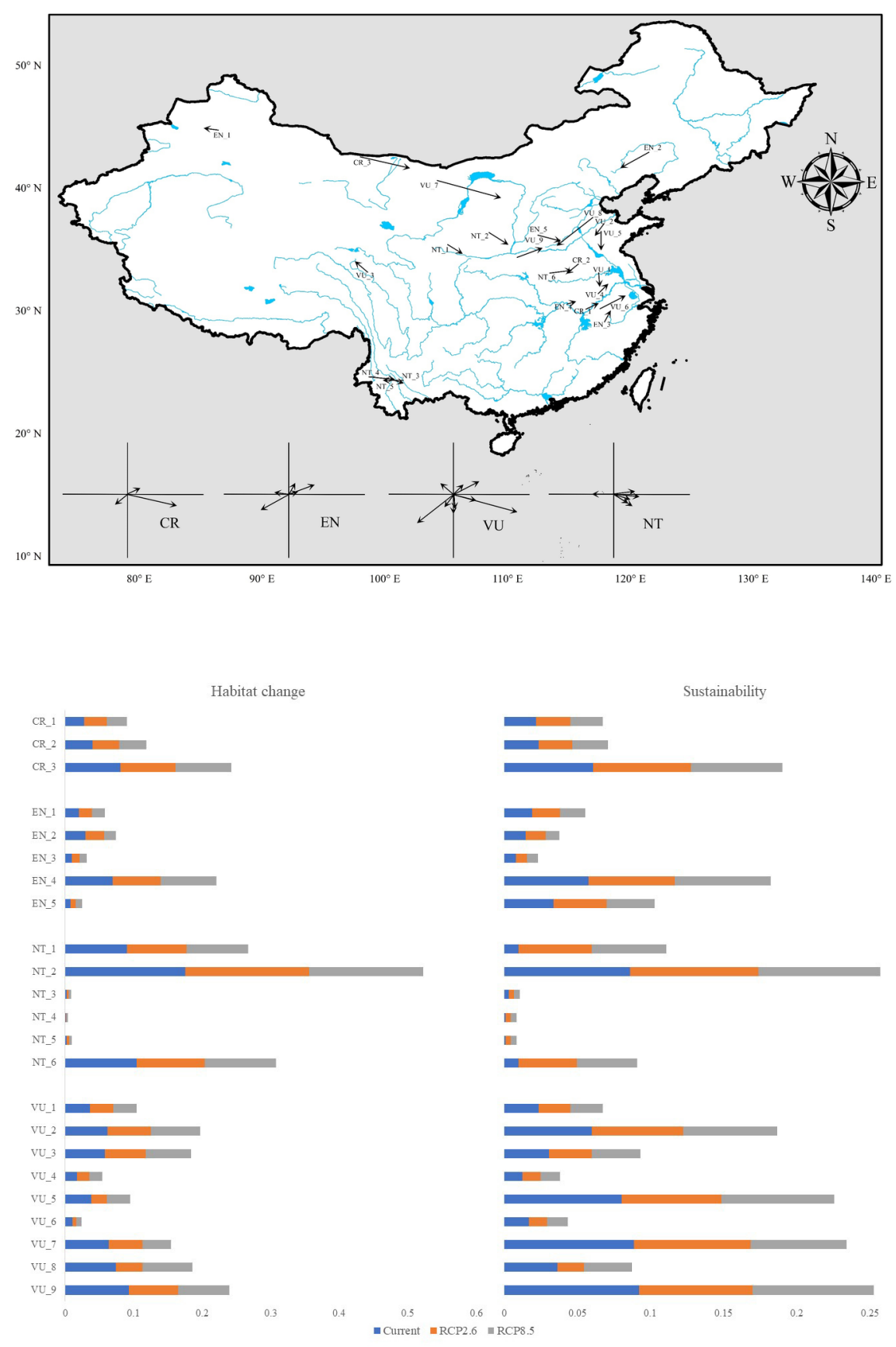

Fig. 5.(a) The shift of the population centroid in the suitable area and (b) mean suitability change and the habitat change in different scenarios

1. 


\section{Discussion}

\section{The effect of climate change}

The result demonstrates that the habitat area of migratory birds will significantly reduce in future, which mainly due to climate change (Gill et al., 2019). Migratory species are more responsive to climate change, as their migration process may be closely related to climate (Dunn et al., 2009).

In summary, temperature plays a great role on the distribution of migratory birds. Therefore, we investigated the importance of environmental variables in 3 different climate zone (east part of south temperate zone(STZ), middle subtropical zone(MSZ) and middle tropical zone(MTZ)). Simultaneously, the environment variables differences in 6 basin (Haihe River Basin, Yellow River Basin, Huaihe River Basin, Yangtze River Basin, Southeast Basin and Pearl River Basin) were also considered. We selected the most important variables firstly and then calculated the percent contribution of variables to figure out the constraint of migratory birds in different regions.

\subsubsection{How does climate influence the basins?}

The habitat area will decline most in the Yangtze River and Pearl River basins of the southern and the area will increase most dramatically in the Huaihe River basins (Fig.6). The area of habitat loss in the Yangtze River basin will reduce mostly $58880 \mathrm{~km}^{2}$ in future. The Pearl River basin and the Yellow River basin will decrease $34589 \mathrm{~km}^{2}$ and $10287 \mathrm{~km}^{2}$ in future. Yangtze River basin will loss $9.74 \%$ of the total habitat area in the basin. Pearl River basin will loss $13.21 \%$ of the total habitat area in the basin. And Yellow River basin will loss $9.83 \%$ of the total habitat area in the basin. The habitat area of the Huaihe River basin will increase $13218 \mathrm{~km}^{2}$, accounting for $8.16 \%$ of the total habitat area in this basin. The decrement of habitat leads to the overlap of living spaces between birds and humans (Flottum et al., 2016; Short et al., 2011).

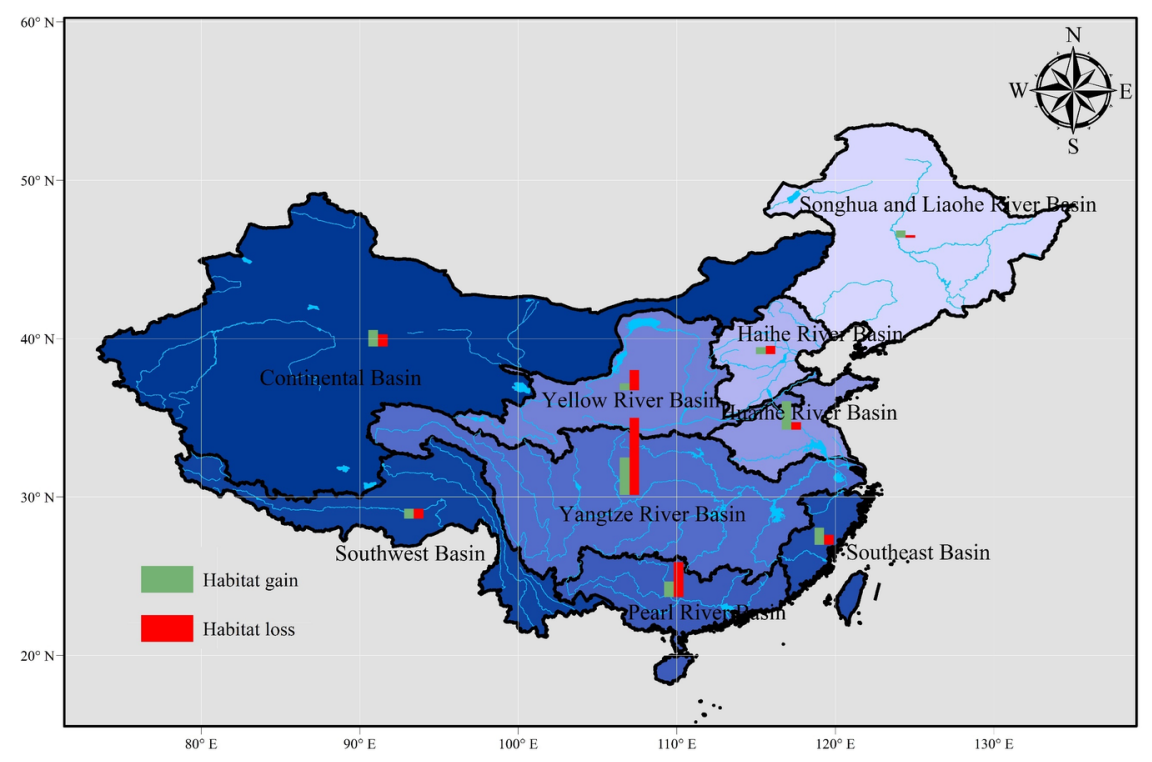

Fig. 6.The change of habitat in different basins

The total migration direction of birds is different from that in different regions. The shifts of population centroid in different regions of habitat are shown in the Fig.7a. The movements of these regions showed that the tendency of the distribution is moving towards the mainstream, which also revealed that the distribution of migratory birds in future scenario will be compressed. The population centroid in Yangtze River basin will move far $44.94 \mathrm{~km}$ towards southeast. The population centroids in Haihe River Basin, Pearl River Basin, 
Yellow River Basin, Southeast Basin and Huaihe River Basin will move 34.26 km, 31.03 km, 25.33 km, 23.48 $\mathrm{km}$ and $16.68 \mathrm{~km}$.
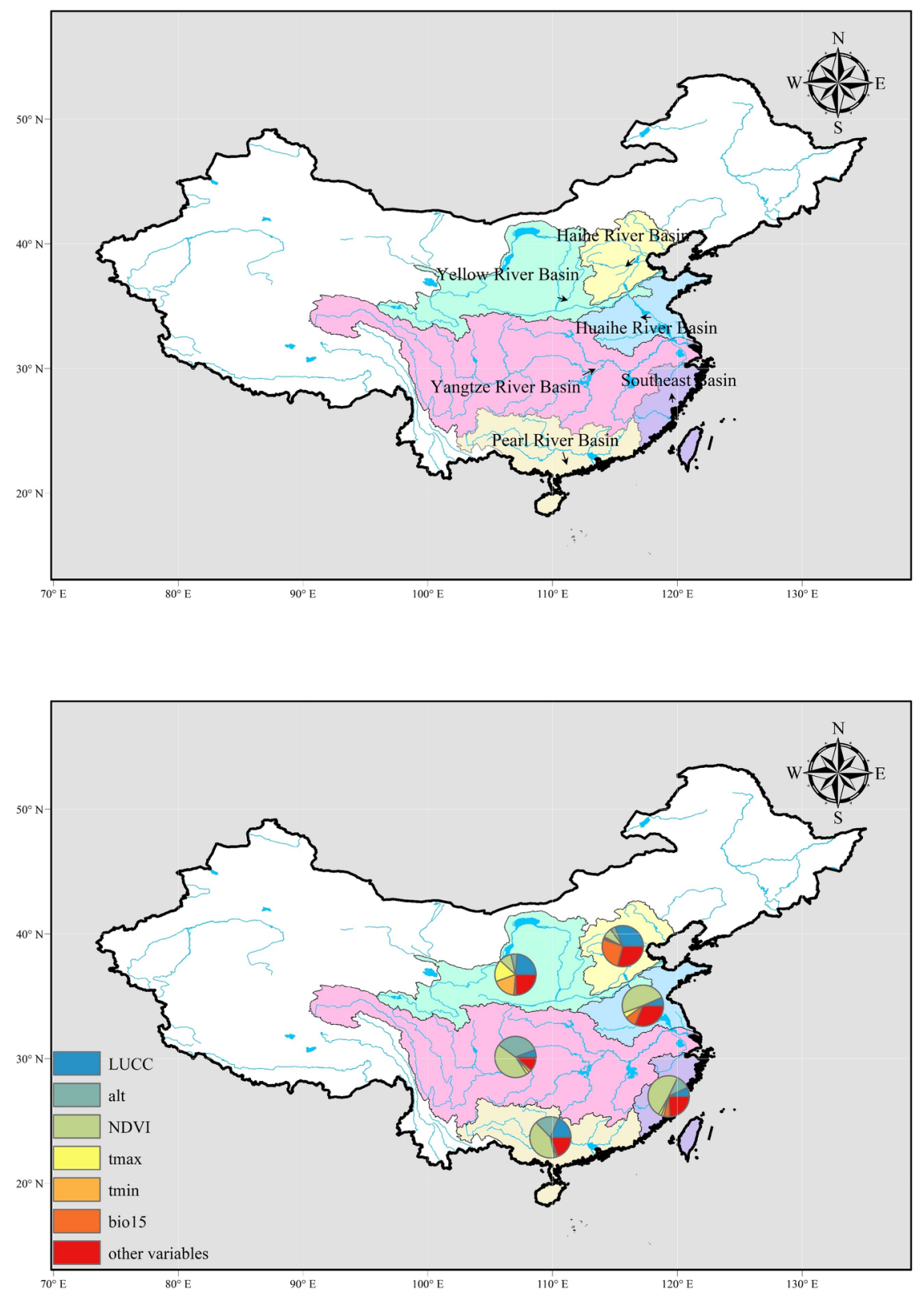

Fig. 7. (a) The shifts of habitat population centroid and(b) the percent contribution of the environment variables in 6 basins.

The result shows that NDVI plays a great role in Yangtze River basin, Huaihe River Basin, Southeast Basin and Pearl River Basin, which the percent contribution for distribution is $43.9 \%, 48.6 \%, 49.1 \%$, and $43.5 \%$ respectively. In these regions, the food is the constraint of the distribution. LUCC is another constraint accounting for $30.9 \%, 23.8 \%$ and $19.6 \%$ importance respectively in Haihe River Basin, Yellow River basin and Pearl River basin. The human activity plays a important role in distribution of these regions. Alt 
is a important variable in Yangtze River basin and Pearl River basin accounting for $34.9 \%$ and $13.7 \%$, respectively. These areas have wide range of elevation.

4.1.2 How does climate change influence the climate zones?

The habitats change mostly in the 3 climate zones (STZ, MSZ, MTZ). The area of habitat has a significant decrease in these 3 climate zones in future. The habitat will loss about $61247 \mathrm{~km}^{2}$ accounting for $7.51 \%$ of MSZ total habitat area. The habitat area of MTZ will reduce $11.43 \%$ about $27955 \mathrm{~km}^{2}$ in future. The habitat area will decrease $6499 \mathrm{~km}^{2}$ which is about $2.17 \%$ of total habitat area of STZ.

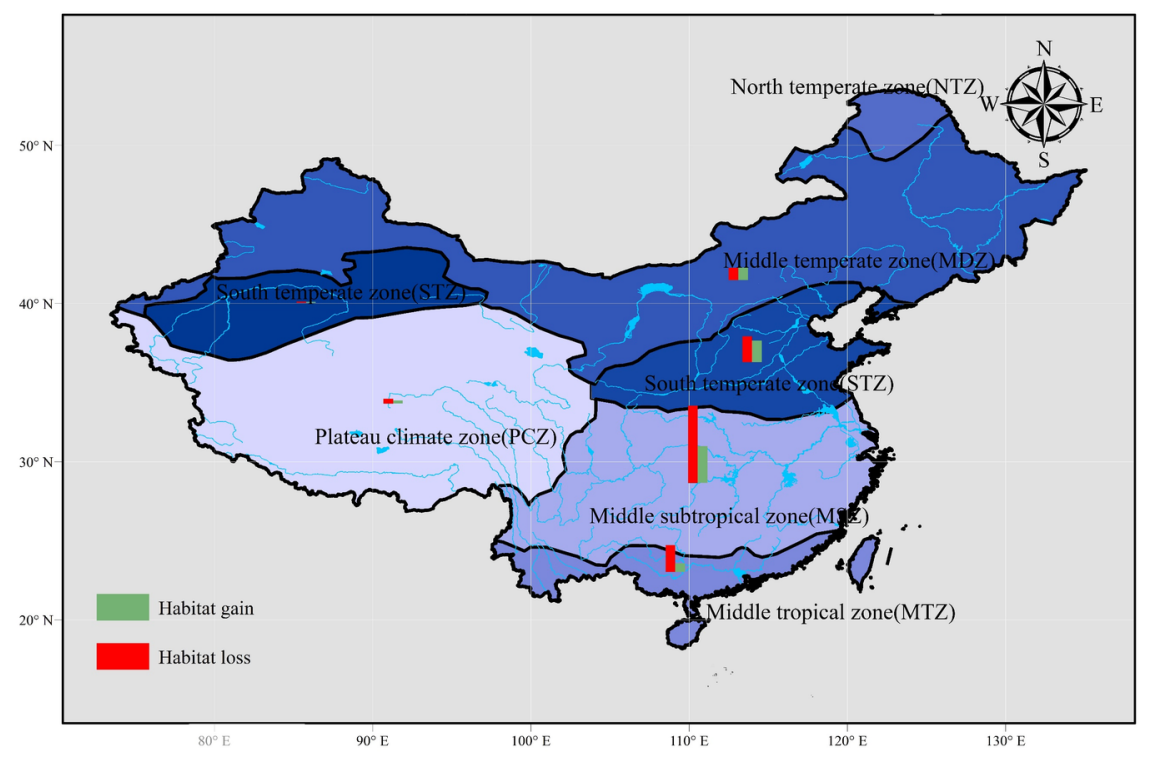

Fig. 8.The change of habitat in different climate zones

The distribution of the STZ will move to east which is consistent with MSZ. The population centroid in STZ will move $44.81 \mathrm{~km}$ and MSZ will move $59.10 \mathrm{~km}$. The distribution in MTZ will move $20.72 \mathrm{~km}$ towards south. The distribution will move to a more suitable area in future. 

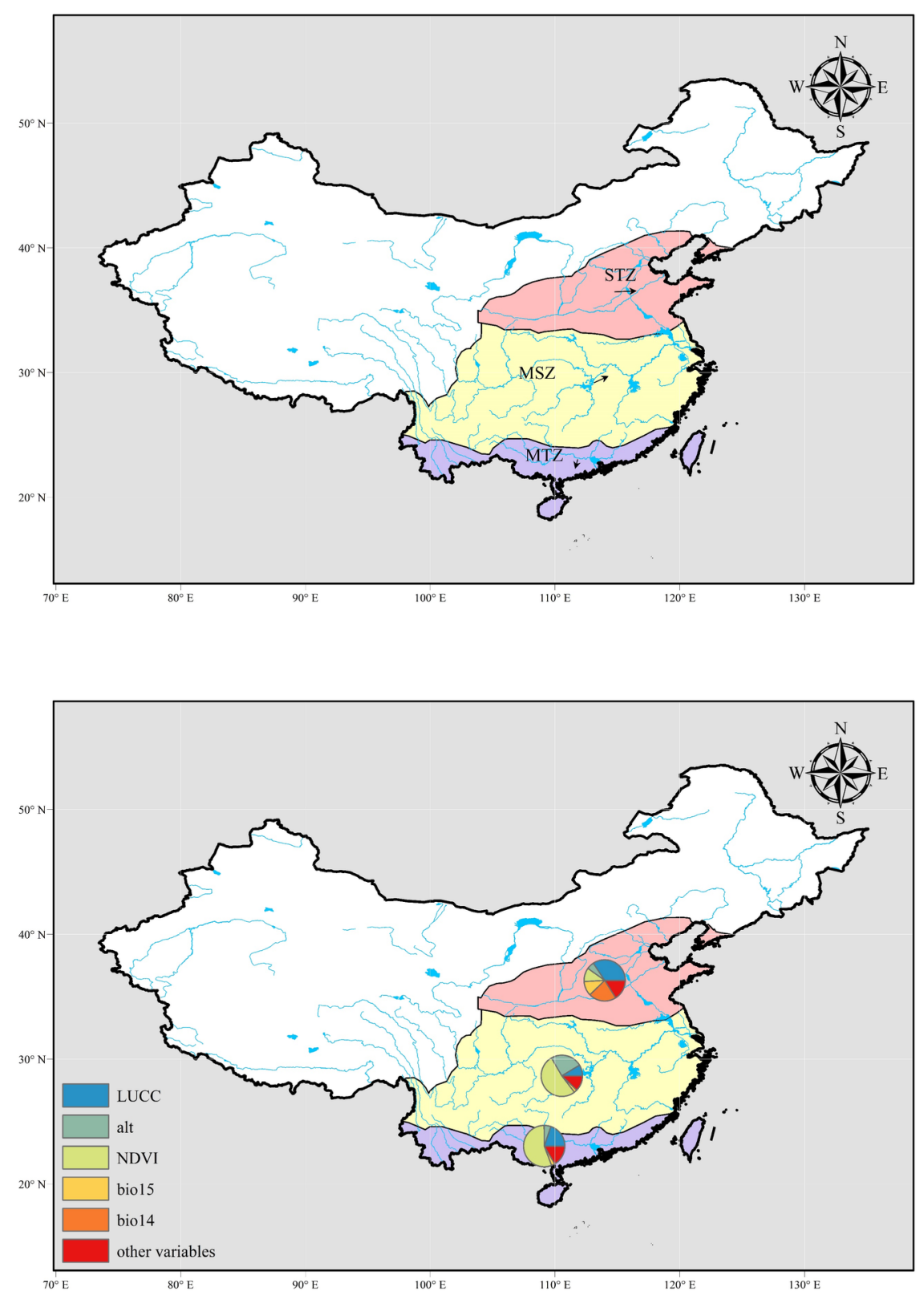

Fig. 9. (a) The shifts of habitat population centroid and(b) the percent contribution of the environment variables in 3 climate zones.

The constraint of STZ distribution is LUCC accounting for $34.3 \%$ importance. The distribution in STZ is also influenced by bio14 and bio15 accounting for $21.6 \%$ and $11.4 \%$,respectively. Seasonal rainfall significantly affected the distribution in this region. NDVI is the most important variable in the distribution of MSZ and MTZ which the percent contribution is $51.6 \%$ and $55.5 \%$ in 2 regions. Alt also plays a great role accounting for $24.6 \%$ in MSZ and LUCC accounts for $19.7 \%$ in MTZ.

The result shows that the reduction of the habitat area and the movement of the population centroid will cause an increase in the distance and the consumption, which forces the birds change their migration time and route. Moreover, some birds may be not even able to achieve migration. The habitat of migratory birds 
in central China trends to move towards east in future, and the habitat of migratory birds in the southern China trends to move towards south.

The result shows that NDVI is an important variable in southern China. The variable shows a great percent contribution to the distribution of migratory birds in southern China, which means the food is the constraint of birds. In the middle China, LUCC plays a great role to the distribution. Especially in the Haihe River Basin and Yellow River Basin, the importance of LUCC accounts for over 30\%, which means human activities influence the distribution greatly. In the Yangtze River Basin of the middle subtropical zone, we can see alt is an important variable to the distribution. Because of the wide area, the altitude varies greatly in the regions.

\section{Implications of birds protection}

\subsubsection{The status of birds protection in China}

Species with broad tolerance may persist or even expand in the changing environments, but migratory birds are sensitive to the environment (Huang et al., 2017; Runge et al., 2015). It is not effective to protect the biodiversity in China though the country has committed great contribution in the remission of biodiversity loss (Young et al., 2014). The main measure of protecting the species is establishing the protected area in China. The identification and delineation of habitat is considered as the cornerstone of the establishment of protected areas. Whether nature reserves works well under climate change has been more important to protect species. Although the number of nature reserves increases recent year, the protective effect is not obvious. For there is no complete system to estimate the effectiveness of nature reserves (Liang et al., 2018c; Ma et al., 2019; Sang et al., 2011). It is more difficult to ensure the effectiveness of protected areas since they move to different places each year.

Considering the climate change and the distribution of the migratory birds, we compared the differences between the nature reserves and the suitable areas(Fig.10). Endangered species are more environmentally sensitive and the population of these species is rare. The migration of these endangered species makes it more difficult for human to protect them effectively.

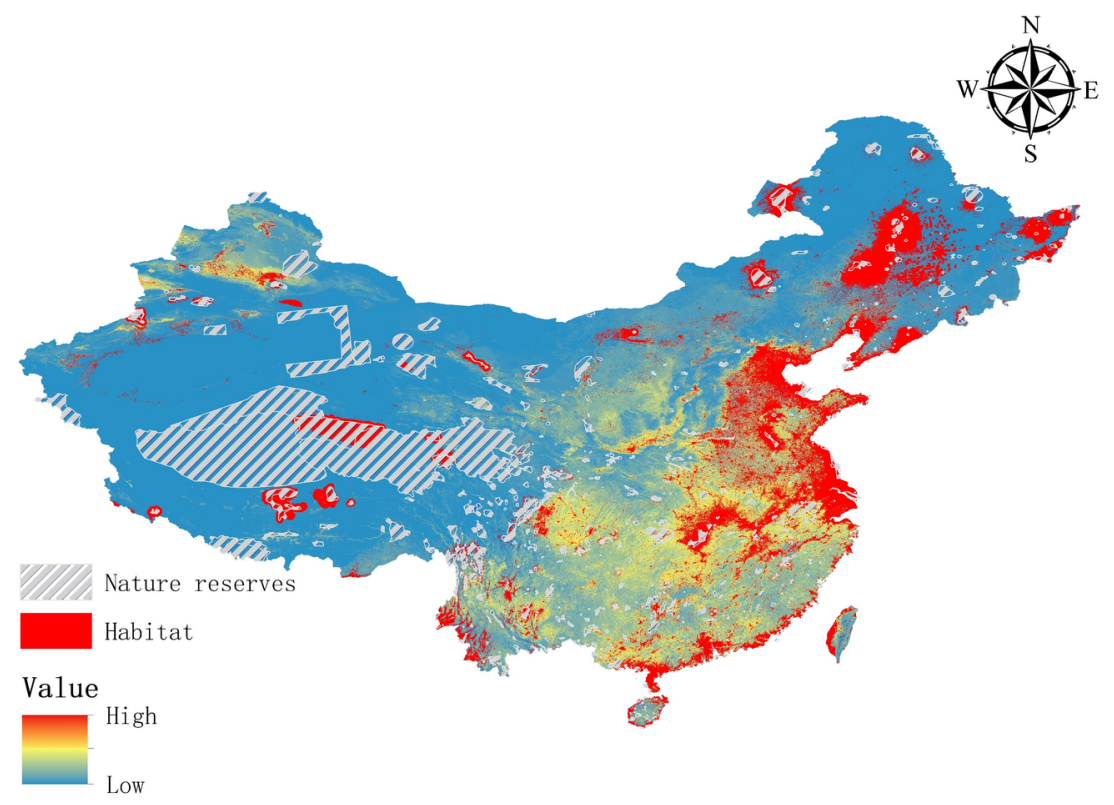

Fig.10. The comparison of nature reserves and suitable areas in China 
Comparing the current distribution of birds and the protected area, we can find out that the suitable areas and nature reserves do not match very well. One of mismatch is that the large number of migratory birds lives in the middle and lower reaches of the Yangtze River Plain but protected area is only located around the Dongting Lake and Poyang Lake. The other of mismatch is the position of habitat and the protected area, there are lots of habitats are not protected. The distribution of protected areas in different regions of China is very uneven, with large areas of protected areas in western China, but the distribution of birds is mainly concentrated in the eastern of China (Ma et al., 2019). Migratory birds tend to choose plain areas that are easily to fly to and feed successfully, so that they can save energy and have a high probability of survival. The western human population is rare, thus, it is easily to manage the reserves and prevent them from artificial effect. However, the situation in the east is more complex because of its position as the agriculture center and its dense population. The protected areas in the eastern area are scattered and broken, and the connectivity between them is also broken(Sang et al., 2011).

\subsubsection{Strategy for birds protection}

Our results indicate some new views about the impact of climate change on bird populations. Firstly, an effective regulatory frame should be built based on the establishment of protected areas. The area of nature reserves in China increases a lot since 2000, but the protective effect is not effective. There are 2 main reasons for this. The first reason is that the location of nature reserves mismatches the distribution of migratory birds (Ma et al., 2019). China is still in the process of high speed development focusing on the economic activities and the urban expansion, which will reduce the space for birds(Liang et al., 2018b; Liang et al., 2017). The second reason is the lack of rational management for nature reserves. The nature reserves locate in the sparsely populated regions in China, which leads to few workers in the large area (Shen et al., 2015). Effective conservation measures must be established for the protection of species, not only to establish effective nature reserves, but also to take effective policies to reduce the impact of climate change on species distribution.

Secondly, different regions should be combined for protection. We can see the similarity of the constraints in different regions. The fact in China is that the nature reserves are isolated from other places. The borders of different provinces, climate zones and the basins are the blind spots for species protection. The mismatching borders among province, basins and climate zones makes it more difficult to manage the cross zones between these areas. Specifically, there are different protection policies to select nature reserves, since China is a wide country with different regulations and standards (Liang et al., 2018a). Which guidelines should the border areas follow and what kind of managements should these areas take are not clear.

Thirdly, the protection of whole birds and individual birds should be distinguished. According to our research, the influence of climate change on species distribution will rise in future. Many species of migratory birds will decrease in distribution and population in future climate scenarios, and may even face the risk of extinction(Pereira et al., 2010; Pimm et al., 2014). Also, some of the species will retain or expand in future. The distribution of each species is different from other species and changes every year. Considering the suitable conditions for the individual species, we can choose a region for this species and control the environmental conditions to meet demand.

Finally, the effective policies should be taken to combat climate change. Climate change has a critical influence on the distribution of birds, therefore, it is necessary to keep the climate relatively stable by making policies. Temperature is the constraint of birds in whole China. The carbon emission making temperature rising has a great influence on the distribution of birds, so it is necessary to reduce the carbon emission (Beringer et al., 2011). Also, the constraint in southern China is NDVI, which suggests that we should keep forest coverage floating within a certain range. At last, biodiversity loss is heavily international problem, all the countries on earth should unite together to protect biodiversity. 


\section{Acknowledgments}

This work was supported by the National Natural Science Foundation of China (51679082, 51979101, 51479072, 51521006), the Hunan Science \& Technology Innovation Program (2018RS3037), the Natural Science Foundation of Hunan Province (2019JJ20002) and the Three Gorges Follow-up Research Project (2017HXXY-05).

\section{References}

Arribas, P., Gutierrez-Canovas, C., Botella-Cruz, M., Canedo-Arguelles, M., Carbonell, J.A., Millan, A., Pallares, S., Velasco, J., Sanchez-Fernandez, D. 2019. Insect communities in saline waters consist of realized but not fundamental niche specialists. Philosophical Transactions Of the Royal Society B-Biological Sciences, 374(1764).

Bauer, S., Hoye, B.J. 2014. Migratory Animals Couple Biodiversity and Ecosystem Functioning Worldwide. Science, 344(6179), 54-+.

Bay, R.A., Harrigan, R.J., Le Underwood, V., Gibbs, H.L., Smith, T.B., Ruegg, K. 2018. Genomic signals of selection predict climate-driven population declines in a migratory bird. Science, 359(6371), 83-+.

Beringer, T., Lucht, W., Schaphoff, S. 2011. Bioenergy production potential of global biomass plantations under environmental and agricultural constraints. Global Change Biology Bioenergy, 3(4), 299-312.

Beumer, L.T., van Beest, F.M., Stelvig, M., Schmidt, N.M. 2019. Spatiotemporal dynamics in habitat suitability of a large Arctic herbivore: Environmental heterogeneity is key to a sedentary lifestyle. Global Ecology and Conservation, 18, 14.

Boisvert-Marsh, L., Perie, C., de Blois, S. 2019. Divergent responses to climate change and disturbance drive recruitment patterns underlying latitudinal shifts of tree species. Journal Of Ecology, 107(4), 1956-1969.

Both, C., Van Turnhout, C.A.M., Bijlsma, R.G., Siepel, H., Van Strien, A.J., Foppen, R.P.B. 2010. Avian population consequences of climate change are most severe for long-distance migrants in seasonal habitats. Proceedings Of the Royal Society B-Biological Sciences, 277(1685), 1259-1266.

Bowler, D.E., Heldbjerg, H., Fox, A.D., de Jong, M., Bohning-Gaese, K. 2019. Long-term declines of European insectivorous bird populations and potential causes. Conservation biology : the journal of the Society for Conservation Biology, 33(5), 1120-1130.

Brawn, J.D., Benson, T.J., Stager, M., Sly, N.D., Tarwater, C.E. 2017. Impacts of changing rainfall regime on the demography of tropical birds. Nature Climate Change, 7(2), 133-+.

Cohen, J.M., Lajeunesse, M.J., Rohr, J.R. 2018. A global synthesis of animal phenological responses to climate change. Nature Climate Change, 8(3), 224-+.

Collins, S.D., Abbott, J.C., McIntyre, N.E. 2017. Quantifying the degree of bias from using county-scale data in species distribution modeling: Can increasing sample size or using county-averaged environmental data reduce distributional overprediction? Ecology and Evolution, 7(15), 6012-6022.

Dudik, M., Phillips, S.J., Schapire, R.E. 2007. Maximum entropy density estimation with generalized regularization and an application to species distribution modeling. Journal Of Machine Learning Research, $8,1217-1260$.

Dudik, M., Phillips, S.J., Schapire, R.E. 2004. Performance guarantees for regularized maximum entropy density estimation. in: Learning Theory, Proceedings, (Eds.) J. ShaweTaylor, Y. Singer, Vol. 3120, pp. $472-486$.

Dugger, K.M., Forsman, E.D., Franklin, A.B., Davis, R.J., White, G.C., Schwarz, C.J., Burnham, K.P., Nichols, J.D., Hines, J.E., Yackulic, C.B., Doherty, P.F., Jr., Bailey, L., Clark, D.A., Ackers, S.H., Andrews, 
L.S., Augustine, B., Biswell, B.L., Blakesley, J., Carlson, P.C., Clement, M.J., Diller, L.V., Glenn, E.M., Green, A., Gremel, S.A., Herter, D.R., Higley, J.M., Hobson, J., Horn, R.B., Huyvaert, K.P., McCafferty, C., McDonald, T., McDonnell, K., Olson, G.S., Reid, J.A., Rockweit, J., Ruiz, V., Saenz, J., Sovern, S.G. 2016. The effects of habitat, climate, and Barred Owls on long-term demography of Northern Spotted Owls. Condor, 118(1), 57-116.

Dunn, R.R., Harris, N.C., Colwell, R.K., Koh, L.P., Sodhi, N.S. 2009. The sixth mass coextinction: are most endangered species parasites and mutualists? Proceedings Of the Royal Society B-Biological Sciences, 276(1670), 3037-3045.

Elith, J., Phillips, S.J., Hastie, T., Dudik, M., Chee, Y.E., Yates, C.J. 2011. A statistical explanation of MaxEnt for ecologists. Diversity and Distributions, 17(1), 43-57.

Fecchio, A., Wells, K., Bell, J.A., Tkach, V.V., Lutz, H.L., Weckstein, J.D., Clegg, S.M., Clark, N.J. 2019. Climate variation influences host specificity in avian malaria parasites. Ecology Letters, 22(3), 547-557.

Finch, T., Butler, S.J., Franco, A.M.A., Cresswell, W. 2017. Low migratory connectivity is common in long-distance migrant birds. Journal Of Animal Ecology, 86(3), 662-673.

Flottum, K., Gasper, D., St Clair, A.L. 2016. Synthesizing a policy-relevant perspective from the three IPCC "Worlds"-A comparison of topics and frames in the SPMs of the Fifth Assessment Report. Global Environmental Change-Human And Policy Dimensions, 38, 118-129.

Fourcade, Y., Engler, J.O., Rodder, D., Secondi, J. 2014. Mapping Species Distributions with MAXENT Using a Geographically Biased Sample of Presence Data: A Performance Assessment of Methods for Correcting Sampling Bias. Plos One, 9(5).

Fournier, A., Penone, C., Pennino, M.G., Courchamp, F. 2019. Predicting future invaders and future invasions. Proceedings Of the National Academy Of Sciences Of the United States Of America, 116(16), 7905-7910.

Garnett, S.T., Crowley, G.M., Stattersfield, A.J. 2003. Changes in the conservation status of Australian birds resulting from differences in taxonomy, knowledge and the definitions of threat. Biological Conservation, $113(2), 269-276$.

Gill, J.A., Alves, J.A., Gunnarsson, T.G. 2019. Mechanisms driving phenological and range change in migratory species. Philosophical Transactions Of the Royal Society B-Biological Sciences, 374(1781).

Hewson, C.M., Thorup, K., Pearce-Higgins, J.W., Atkinson, P.W. 2016. Population decline is linked to migration route in the Common Cuckoo. Nature Communications, 7.

Hoffmann, A.A., Sgro, C.M. 2011. Climate change and evolutionary adaptation. Nature, 470(7335), 479-485.

Huang, Q., Sauer, J.R., Dubayah, R.O. 2017. Multidirectional abundance shifts among North American birds and the relative influence of multifaceted climate factors. Global Change Biology, 23(9), 3610-3622.

Ims, R.A., Henden, J.-A., Stromeng, M.A., Thingnes, A.V., Garmo, M.J., Jepsen, J.U. 2019. Arctic greening and bird nest predation risk across tundra ecotones. Nature Climate Change, 9(8), 607-+.

Jacome, G., Vilela, P., Yoo, C. 2019. Present and future incidence of dengue fever in Ecuador nationwide and coast region scale using species distribution modeling for climate variability's effect. Ecological Modelling, 400, 60-72.

Jetz, W., Wilcove, D.S., Dobson, A.P. 2007. Projected impacts of climate and land-use change on the global diversity of birds. Plos Biology, 5(6), 1211-1219.

Kentie, R., Coulson, T., Hooijmeijer, J.C.E.W., Howison, R.A., Loonstra, A.H.J., Verhoeven, M.A., Both, C., Piersma, T. 2018. Warming springs and habitat alteration interact to impact timing of breeding and population dynamics in a migratory bird. Global Change Biology, 24(11), 5292-5303. 
Keogan, K., Daunt, F., Wanless, S., Phillips, R.A., Walling, C.A., Agnew, P., Ainley, D.G., Anker-Nilssen, T., Ballard, G., Barrett, R.T., Barton, K.J., Bech, C., Becker, P., Berglund, P.A., Bollache, L., Bond, A.L., Bouwhuis, S., Bradley, R.W., Burr, Z.M., Camphuysen, K., Catry, P., Chiaradia, A., Christensen-Dalsgaard, S., Cuthbert, R., Dehnhard, N., Descamps, S., Diamond, T., Divoky, G., Drummond, H., Dugger, K.M., Dunn, M.J., Emmerson, L., Erikstad, K.E., Fort, J., Fraser, W., Genovart, M., Gilg, O., Gonzalez-Solis, J., Granadeiro, J.P., Gremillet, D., Hansen, J., Hanssen, S.A., Harris, M., Hedd, A., Hinke, J., Igual, J.M., Jahncke, J., Jones, I., Kappes, P.J., Lang, J., Langset, M., Lescroel, A., Lorentsen, S.H., Lyver, P.O., Mallory, M., Moe, B., Montevecchi, W.A., Monticelli, D., Mostello, C., Newell, M., Nicholson, L., Nisbet, I., Olsson, O., Oro, D., Pattison, V., Poisbleau, M., Pyk, T., Quintana, F., Ramos, J.A., Ramos, R., Reiertsen, T.K., Rodriguez, C., Ryan, P., Sanz-Aguilar, A., Schmidt, N.M., Shannon, P., Sittler, B., Southwell, C., Surman, C., Svagelj, W.S., Trivelpiece, W., Warzybok, P., Watanuki, Y., Weimerskirch, H., Wilson, P.R., Wood, A.G., Phillimore, A.B., Lewis, S. 2018. Global phenological insensitivity to shifting ocean temperatures among seabirds. Nature Climate Change, 8(4), 313-+.

Kirby, J.S., Stattersfield, A.J., Butchart, S.H.M., Evans, M.I., Grimmett, R.F.A., Jones, V.R., O'Sullivan, J., Tucker, G.M., Newton, I. 2008. Key conservation issues for migratory land- and waterbird species on the world's major flyways. Bird Conservation International, 18, S49-S73.

Lehikoinen, P., Santangeli, A., Jaatinen, K., Rajasarkka, A., Lehikoinen, A. 2019. Protected areas act as a buffer against detrimental effects of climate change-Evidence from large-scale, long-term abundance data. Global Change Biology, 25(1), 304-313.

Liang, J., Gao, X., Zeng, G., Hua, S., Zhong, M., Li, X., Li, X. 2018a. Coupling Modern Portfolio Theory and Marxan enhances the efficiency of Lesser White-fronted Goose's (Anser erythropus) habitat conservation. Scientific Reports, 8.

Liang, J., He, X., Zeng, G., Zhong, M., Gao, X., Li, X., Li, X., Wu, H., Feng, C., Xing, W., Fang, Y., Mo, D. 2018b. Integrating priority areas and ecological corridors into national network for conservation planning in China. Science of the Total Environment, 626, 22-29.

Liang, J., Xing, W., Zeng, G., Li, X., Peng, Y., Li, X., Gao, X., He, X. 2018c. Where will threatened migratory birds go under climate change? Implications for China's national nature reserves. Science Of the Total Environment, 645, 1040-1047.

Liang, J., Zhong, M., Zeng, G., Chen, G., Hua, S., Li, X., Yuan, Y., Wu, H., Gao, X. 2017. Risk management for optimal land use planning integrating ecosystem services values: A case study in Changsha, Middle China. Science of the Total Environment, 579, 1675-1682.

Liu, Q., Yang, Z., Wang, C., Han, F. 2019. Temporal-Spatial Variations and Influencing Factor of Land Use Change in Xinjiang, Central Asia, from 1995 to 2015. Sustainability, 11(3).

Ma, Z., Chen, Y., Melville, D.S., Fan, J., Liu, J., Dong, J., Tan, K., Cheng, X., Fuller, R.A., Xiao, X., Li, B. 2019. Changes in area and number of nature reserves in China. Conservation Biology, 33(5), 1066-1075.

Mammola, S., Goodacre, S.L., Isaia, M. 2018. Climate change may drive cave spiders to extinction. Ecography, 41(1), 233-243.

Manish, K., Pandit, M.K. 2019. Identifying conservation priorities for plant species in the Himalaya in current and future climates: A case study from Sikkim Himalaya, India. Biological Conservation, 233, 176-184.

Moran, D., Kanemoto, K. 2017. Identifying species threat hotspots from global supply chains. Nature Ecology \& Evolution, 1(1).

Myers, N., Mittermeier, R.A., Mittermeier, C.G., da Fonseca, G.A.B., Kent, J. 2000. Biodiversity hotspots for conservation priorities. Nature, 403(6772), 853-858. 
Northrup, J.M., Rivers, J.W., Yang, Z.Q., Betts, M.G. 2019. Synergistic effects of climate and land-use change influence broad-scale avian population declines. Global Change Biology, 25(5), 1561-1575.

Pacifici, M., Visconti, P., Butchart, S.H.M., Watson, J.E.M., Cassola, F.M., Rondinini, C. 2017. Species' traits influenced their response to recent climate change. Nature Climate Change, 7(3), 205-+.

Panda, R.M., Behera, M.D. 2019. Assessing harmony in distribution patterns of plant invasions: a case study of two invasive alien species in India. Biodiversity and Conservation, 28(8-9), 2245-2258.

Pearson, R.G., Phillips, S.J., Loranty, M.M., Beck, P.S.A., Damoulas, T., Knight, S.J., Goetz, S.J. 2013. Shifts in Arctic vegetation and associated feedbacks under climate change. Nature Climate Change, 3(7), 673-677.

Pereira, H.M., Leadley, P.W., Proenca, V., Alkemade, R., Scharlemann, J.P.W., Fernandez-Manjarres, J.F., Araujo, M.B., Balvanera, P., Biggs, R., Cheung, W.W.L., Chini, L., Cooper, H.D., Gilman, E.L., Guenette, S., Hurtt, G.C., Huntington, H.P., Mace, G.M., Oberdorff, T., Revenga, C., Rodrigues, P., Scholes, R.J., Sumaila, U.R., Walpole, M. 2010. Scenarios for Global Biodiversity in the 21st Century. Science, 330(6010), 1496-1501.

Phillips, S.J., Anderson, R.P., Schapire, R.E. 2006. Maximum entropy modeling of species geographic distributions. Ecological Modelling, 190(3-4), 231-259.

Phillips, S.J., Dudik, M. 2008. Modeling of species distributions with Maxent: new extensions and a comprehensive evaluation. Ecography, 31(2), 161-175.

Pimm, S.L., Jenkins, C.N., Abell, R., Brooks, T.M., Gittleman, J.L., Joppa, L.N., Raven, P.H., Roberts, C.M., Sexton, J.O. 2014. The biodiversity of species and their rates of extinction, distribution, and protection. Science, 344(6187), 987-+.

Roberts, C.P., Allen, C.R., Angeler, D.G., Twidwell, D. 2019. Shifting avian spatial regimes in a changing climate. Nature Climate Change, 9(7), 562-+.

Rosen, R.A., Guenther, E. 2016. The energy policy relevance of the 2014 IPCC Working Group III report on the macro-economics of mitigating climate change. Energy Policy, 93, 330-334.

Runge, C.A., Watson, J.E.M., Butchart, S.H.M., Hanson, J.O., Possingham, H.P., Fuller, R.A. 2015. Protected areas and global conservation of migratory birds. Science, 350(6265), 1255-1258.

Rushing, C.S., Ryder, T.B., Marra, P.P. 2016. Quantifying drivers of population dynamics for a migratory bird throughout the annual cycle. Proceedings Of the Royal Society B-Biological Sciences, 283(1823).

Russell, D.J.F., Wanless, S., Collingham, Y.C., Anderson, B.J., Beale, C., Reid, J.B., Huntley, B., Hamer, K.C. 2015. Beyond climate envelopes: bio-climate modelling accords with observed 25-year changes in seabird populations of the British Isles. Diversity And Distributions, 21(2), 211-222.

Saino, N., Ambrosini, R., Rubolini, D., von Hardenberg, J., Provenzale, A., Hueppop, K., Hueppop, O., Lehikoinen, A., Lehikoinen, E., Rainio, K., Romano, M., Sokolov, L. 2011. Climate warming, ecological mismatch at arrival and population decline in migratory birds. Proceedings Of the Royal Society B-Biological Sciences, 278(1707), 835-842.

Sanchez-Bayo, F., Wyckhuys, K.A.G. 2019. Worldwide decline of the entomofauna: A review of its drivers. Biological Conservation, 232, 8-27.

Sang, W.G., Ma, K.P., Axmacher, J.C. 2011. Securing a Future for China's Wild Plant Resources. Bioscience, 61(9), 720-725.

Saupe, E.E., Farnsworth, A., Lunt, D.J., Sagoo, N., Pham, K.V., Field, D.J. 2019. Climatic shifts drove major contractions in avian latitudinal distributions throughout the Cenozoic. Proceedings Of the National Academy Of Sciences Of the United States Of America, 116(26), 12895-12900. 
Shcheglovitova, M., Anderson, R.P. 2013. Estimating optimal complexity for ecological niche models: A jackknife approach for species with small sample sizes. Ecological Modelling, 269, 9-17.

Shen, G.Z., Pimm, S.L., Feng, C.Y., Ren, G.F., Liu, Y.P., Xu, W.T., Li, J.Q., Si, X.F., Xie, Z.Q. 2015. Climate change challenges the current conservation strategy for the giant panda. Biological Conservation, 190, 43-50.

Short, F.T., Polidoro, B., Livingstone, S.R., Carpenter, K.E., Bandeira, S., Bujang, J.S., Calumpong, H.P., Carruthers, T.J.B., Coles, R.G., Dennison, W.C., Erftemeijer, P.L.A., Fortes, M.D., Freeman, A.S., Jagtap, T.G., Kamal, A.M., Kendrick, G.A., Kenworthy, W.J., La Nafie, Y.A., Nasution, I.M., Orth, R.J., Prathep, A., Sanciangco, J.C., van Tussenbroek, B., Vergara, S.G., Waycott, M., Zieman, J.C. 2011. Extinction risk assessment of the world's seagrass species. Biological Conservation, 144(7), 1961-1971.

Spooner, F.E.B., Pearson, R.G., Freeman, R. 2018. Rapid warming is associated with population decline among terrestrial birds and mammals globally. Global Change Biology, 24(10), 4521-4531.

Taubert, F., Fischer, R., Groeneveld, J., Lehmann, S., Muller, M.S., Rodig, E., Wiegand, T., Huth, A. 2018. Global patterns of tropical forest fragmentation. Nature, 554(7693), 519-+.

Thorson, J.T. 2019. Forecast skill for predicting distribution shifts: A retrospective experiment for marine fishes in the Eastern Bering Sea. Fish And Fisheries, 20(1), 159-173.

Title, P.O., Bemmels, J.B. 2018. ENVIREM: an expanded set of bioclimatic and topographic variables increases flexibility and improves performance of ecological niche modeling. Ecography, 41(2), 291-307.

Vale, C.G., Tarroso, P., Brito, J.C. 2014. Predicting species distribution at range margins: testing the effects of study area extent, resolution and threshold selection in the Sahara-Sahel transition zone. Diversity and Distributions, 20(1), 20-33.

Vickery, J.A., Ewing, S.R., Smith, K.W., Pain, D.J., Bairlein, F., Skorpilova, J., Gregory, R.D. 2014. The decline of Afro-Palaearctic migrants and an assessment of potential causes. Ibis, 156(1), 1-22.

Wang, J.W., Wang, F., Wang, R.L., Zhang, J., Zhao, X., Yang, H., Yang, W., Yang, C.P., Wang, Z.Y., Li, A.N. 2019. Modeling the effects of bioclimatic characteristics and distribution on the occurrence of Cyrtotrachelus buqueti in the Sichuan Basin. Global Ecology And Conservation, 17.

Wilson, K.L., Skinner, M.A., Lotze, H.K. 2019. Projected 21st-century distribution of canopy-forming seaweeds in the Northwest Atlantic with climate change. Diversity And Distributions, 25(4), 582-602.

Xu, W., Xiao, Y., Zhang, J., Yang, W., Zhang, L., Hull, V., Wang, Z., Zheng, H., Liu, J., Polasky, S., Jiang, L., Xiao, Y., Shi, X., Rao, E., Lu, F., Wang, X., Daily, G.C., Ouyang, Z. 2017. Strengthening protected areas for biodiversity and ecosystem services in China. Proceedings Of the National Academy Of Sciences Of the United States Of America, 114(7), 1601-1606.

Yalcin, S., Leroux, S.J. 2018. An empirical test of the relative and combined effects of land-cover and climate change on local colonization and extinction. Global Change Biology, 24(8), 3849-3861.

Yong, D.L., Jain, A., Liu, Y., Iqbal, M., Choi, C.Y., Crockford, N.J., Millington, S., Provencher, J. 2018. Challenges and opportunities for transboundary conservation of migratory birds in the East AsianAustralasian flyway. Conservation Biology, 32(3), 740-743.

Young, R.P., Hudson, M.A., Terry, A.M.R., Jones, C.G., Lewis, R.E., Tatayah, V., Zuel, N., Butchart, S.H.M. 2014. Accounting for conservation: Using the IUCN Red List Index to evaluate the impact of a conservation organization. Biological Conservation, 180, 84-96.

Yu, F.Y., Wang, T.J., Groen, T.A., Skidmore, A.K., Yang, X.F., Ma, K.P., Wu, Z.F. 2019. Climate and land use changes will degrade the distribution of Rhododendrons in China. Science of the Total Environment, $659,515-528$. 